\title{
Educación Pictórica como Alternativa a la Comunicación en Niños Sordos
}

\section{Pictorial Education as an Alternative to Communication in Deaf Children}

\author{
Julio Jaime Flores-Rivas * \\ Fidel González-Quiñones
}

Universidad Autónoma de Chihuahua, México

\begin{abstract}
Esta investigación analiza en qué medida la educación pictórica puede ayudar a niños sordos en su desarrollo gráfico expresivo mediante la pintura, e identifica si existe relación con cambios en su nivel de interacción social y su comprensión del vocabulario de la Lengua de Señas Mexicana (LSM). Para ello se utilizó un diseño experimental de tipo preexperimental y de preprueba posprueba con un solo grupo, contando con la participación de siete menores de edad sordos en edades entre los 6 y 12 años, todos hijos de padres oyentes. Esta investigación es de corte mixto y presenta observaciones similares en los resultados de su componente cualitativo y del cuantitativo. Se observó una mejora en los resultados de la variable comprensión del vocabulario, un aumento en el desarrollo técnico-expresivo del infante y se registró un aumento en la participación de creaciones colectivas, creatividad en el uso de los materiales y los elementos del lenguaje plástico. Sobre la repercusión que tendría este tratamiento experimental en el nivel de interacción social y comprensión del vocabulario de los participantes hubo concordancia entre los datos recabados de manera cualitativa y cuantitativa, y, sobre la percepción de aumento en estas habilidades. Finalmente, se presentan algunos hallazgos importantes que no se habían contemplado en los objetivos iniciales.
\end{abstract}

Descriptores: Sordo; Educación especial; Arte; Expresión corporal; Educación artística.

This research analyzes the extent to which pictorial education can help deaf children in their expressive graphic development through painting, and identifies if this is related to changes in their level of social interaction and their understanding of the vocabulary of Mexican Sign Language (MSL). For this, an experimental design of pre-experimental type and post-test pre-test with a single group was used, with the participation of seven deaf minors between the ages of 6 and 12, all children of hearing parents. This research is mixed-cut and presents similar observations in the results of its qualitative and quantitative components. There was an improvement in the results of the variable understanding of vocabulary, an increase in the technicalexpressive development of the infant and there was an increase in the participation of collective creations, creativity in the use of materials and elements of plastic language. On the impact that this experimental treatment would have on the level of social interaction and understanding of the vocabulary of the participants, there was an agreement between the data collected qualitatively and quantitatively, and, on the perception of an increase in these skills. Finally, some important findings that were not contemplated in the initial objectives are presented.

Keywords: Deaf; Special needs education; Art; Movement education; Art education.

*Contacto: goro_fuyita@hotmail.com

ISSN: 1696-4713

www.rinace.net/reice/

revistas.uam.es/reice
Recibido: $\quad 19$ de mayo 2019

$1^{\text {a }}$ Evaluación: 6 de junio 2019

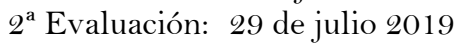

Aceptado: $\quad 24$ de agosto 2019 


\section{Introducción}

Actualmente la principal forma en la que los sordos se comunican con las personas oyentes es mediante lenguaje escrito; sin embargo, diversos estudios han demostrado que los sordomudos terminan su educación básica con un desempeño muy por debajo de la media (Fernández, 2009, 2014; Gálan, Romero y Buelvas, 2018; Herrera, 2005; Lissi et al., 2011). Otros estudios han demostrado que los sordomudos aprenden hasta tres veces más lento que las personas oyentes y terminan su educación básica con un desempeño menor al resto de sus compañeros (Asensio 1989; Conrad 1979; Marschark y Harrys, 1996). El lenguaje, sea del tipo que fuere, "es un elemento fundamental en los procesos de construcción del conocimiento, y la lengua materna es el principal medio de comunicación que posee el niño para vincularse con el ambiente escolar" (Cú Balán, Contreras y Rosado, 2007, p. 68) por lo cual es importante dotarlos con otra forma de expresión, en este caso el arte.

En este estudio, la pintura y dibujo son los medios de expresión que se les da a niños sordos para que esta misma la puedan ejercer como medio de comunicación alterna a la escritura, de este modo se busca que la expresión sea un hábito en ellos, algo que esté integrado en su vida cotidiana, además, mediante el tratamiento experimental se pretende que puedan mejorar su capacidad de interacción social y la comprensión del vocabulario, habilidades que les servirán para posteriormente dominar el lenguaje escrito. Domínguez y Leybaert (2014) concibieron al vocabulario y la gramática como limitantes para la comprensión lectora, por otro lado, Alegre y Villar (2019, p. 6) señalan que "las personas con dificultades auditivas tienen interferencias en la comunicación que afectan sus percepciones y conocimientos, que resultan fundamentales para detectar problemas de aprendizaje" de ahí la importancia de que este programa experimental tenga como objetivo atenuar una de estas limitantes para los niños sordos.

Existen programas de atención basados en la pintura y sus efectos en niños sordos, diversos autores nos explican que las artes plásticas tienen múltiples beneficios para varios aspectos de la vida y desarrollo del niño sordo, demostrando que las artes plásticas son un conjunto de conocimientos activos, emocionales y de relación con los medios de relación social (Camargo-Pérez y Dimas-Padilla, 2014; Corasi, Guerra y Paz, 2014; Segura, 2002). Por eso las artes se relacionan efectivamente con el resto de las demás asignaturas mejorando el desarrollo social del niño.

Según Read (1969), los niños dibujan para satisfacer su necesidad de expresión (el cual lo considera innato en ellos) liberando así su ansiedad, sus miedos y sus problemas. Por eso consideramos que el dibujo y la pintura son parte muy importante en la expresión emocional del niño, una manera innata en la cual puedan expresar sus condiciones y sentimientos dejando atrás todo mecanismo de dificultad gramatical expresivo que el niño oyente ya conoce. La expresión plástica, según Alcaide (2003), refuerza las nociones de identidad y transforma las conductas antisociales del niño, facilitando su socialización proporcionando un lenguaje alternativo con la eficacia primordial, que desde tiempos ancestrales han ayudado al hombre a comunicarse entre sí sin el conocimiento gramatical acostumbrado en las personas actuales.

Dados los antecedentes planteados, surge como objetivo general de este trabajo el investigar de qué manera un curso basado en la educación pictórica puede ayudar a niños sordos en su expresión mediante la pintura, entendiendo la expresión como desarrollo gráfico expresivo y analizar si ello tiene relación con cambios en su nivel de interacción 
social y su comprensión del vocabulario de la Lengua de Señas Mexicana (LSM). Se busca también examinar el impacto que tiene la enseñanza del dibujo y pintura en el desarrollo de la competencia comunicativa en el estudiante sordo.

\section{Revisión de la literatura}

La discapacidad es un constructo que ha cambiado a través del tiempo, hace algunas décadas se trataba a las personas discapacitadas como enfermos, se les segregaba en instituciones residenciales, escuelas especiales o enclaustraba en su propia casa; actualmente la forma de percibir esta condición ha cambiado, de igual forma las soluciones y las políticas públicas, pues ahora se busca incluir en la comunidad a las personas discapacitadas (OMS, 2011). Diversas fuentes señalan que el nivel de discapacidad es dado tanto por las características fisiológicas de las personas, como por su entorno, que lo ayuda o limita en su actividad o participación (OMS, 2001, 201 1; Parra y Luque-Rojas, 2013).

Dentro de la taxonomía de la discapacidad, la discapacidad sensorial se entiende como: "deficiencia en su audición o visión con resultado de una percepción y procesamiento de la información disfuncionales, dificultándoles aspectos cognitivos en la adquisición y manipulación del espacio, en el lenguaje, en la relación personal y de funcionamiento en la comunidad." (Parra y Luque-Rojas, 2013, p. 63). La discapacidad auditiva, es la pérdida de capacidad sensorial que afecta a la capacidad del aprendizaje lingüístico del individuo para la comunicación cotidiana, expresión lingüística y expresión de su pensamiento; esto debido a factores individuales y del contexto (OMS, 2001; Parra y Luque-Rojas, 2013). Aunque los estudios longitudinales son la mejor forma de establecer el impacto que tiene el desarrollo temprano de las habilidades lingüísticas y metalingüísticas en personas sordas, hay pocos trabajos de este tipo y temática específica (Domínguez y Alegría, 2010).

Algunos estudios indican que los niños sordos parecen ser capaces de desarrollar una conciencia fonológica antes de aprender a leer, aunque de una forma más imprecisa en comparación con sus pares oyentes (Domínguez y Leybaert, 2014). Además, los mismos autores identificaron diferencias inter-individuales en la predicción de la adquisición de conciencia fonológica a principios de la adquisición de la lectura tanto en niños sordos como en los oyentes. Colin y colaboradores (2007) trataron de predecir las habilidades de reconocimiento de palabras mediante las habilidades metafonológicas de un modo comparativo entre niños de primaria sordos y oyentes. Ellos proponen que la capacidad de manipular las unidades fonológicas (rimas, sílabas) del idioma materno antes de aprender a leerlo, fomenta el reconocimiento de las palabras en niños sordos (como sucede con los niños oyentes), pero también que la adquisición de la lectura estimula el desarrollo de la conciencia fonológica en mayor medida en los niños sordos que en los oyentes (Domínguez, Rodríguez y Alonso, 2011). Por otra parte, Kyle y Harris (2010), al estudiar por tres años a 29 niños sordos de entre 7 y 8 años, proponen que la habilidad para leer los labios es también un predictor significativo de la habilidad para reconocer palabras.

Bortoi y Brown (2008) hicieron un estudio comparativo entre niños sordos, niños con discapacidad intelectual y sus pares sin trastornos en el desarrollo ni discapacidades, todos entre los 4 y 5 años. Aunque no se encontraron diferencias estadísticamente significativas entre los tres grupos, el grupo con discapacidad intelectual fue el más bajo en calificaciones en todas las áreas, el grupo con pérdida del oído también se puntuó por debajo de sus pares con desarrollo típico, excepto en el dominio motor. Al contrario de esto, existen autores 
que afirmaron que no hay una diferencia comprobable entre la inteligencia de un niño oyente y uno sordo (Martín, 1995), sin embargo, Pérez López (2014) lo atribuye a la diferencia en el número de estímulos a los que están expuestos, ya que el oído es un sentido que se activa de manera involuntaria de forma permanente desde que el niño oyente nace, al contrario de la vista.

Apoyando la postura de que la inteligencia no es mayor o menor sino diferente por la naturaleza igualmente disímil en la que las experiencias y percepciones son recibidas por el cerebro, se toma como base la propuesta de Piaget de la estructura de la inteligencia, descrita por Pérez López (2014, p. 131). Para Swanwick (2015), este tipo de estudios separan la investigación de la educación, las cuales, propone que formen un circulo virtuoso, para que la investigación regrese a la educación y esta sea un acto de constante investigación para la mejora; como una forma de lograrlo, propone el uso del estudio de caso y un ecological framework (campo de trabajo ecológico), es una manera de integrar temas del lenguaje, el aprendizaje y expandir conceptos en el campo de la educación para sordos tomando en cuenta las vulnerabilidades a las que el niño está expuesto desde diferentes niveles.

Investigaciones que siguen esta metodología del estudio de caso, nos permiten conocer a profundidad las necesidades y oportunidades de los niños sordos. Por ejemplo los estudios de Agurto (2012) sobre las inteligencias múltiples, basado en la teoría de Gardner (1993), postulan que las inteligencias más desarrolladas en las personas sordas son: (i) kinestésicocorporal, pues usan todo su cuerpo para expresarse, llegando incluso a tener un desempeño a la par de niños oyentes (Bortoi y Brown, 2008), (ii) espacial, pues tienden a percibir de manera exacta el mundo viso-espacial, según la misma autora: "esta inteligencia incluye la sensibilidad al color, la línea, la forma, el espacio y las relaciones que existen entre estos elementos. Incluye la capacidad de visualizar, de representar de manera gráfica ideas visuales o espaciales" (Bortoi y Brown, 2008, p. 6); por último, desarrollan en gran medida la inteligencia, y (iii) lingüística, pues poseen habilidad para la sintaxis y los usos pragmáticos del lenguaje como la retórica y el metalenguaje, asegura que a estos alumnos les agrada redactar historias, leer, jugar con rimas, realizar trabalenguas y aprenden otros idiomas con facilidad.

Aunque se han realizado diversos estudios para tratar de predecir el éxito académico, son pocos los que se centran en las personas con discapacidad y aún menos los que tratan la temática de los estudiantes sordos, como lo hacen Convertino y colaboradores (2009), quiénes después de realizar un análisis de regresión predictivo, establecieron que se puede predecir el 80\% del éxito escolar de un estudiante con deficiencia auditiva, siguiendo las variables: evaluación de la materia de Inglés (la lengua natal de los participantes del estudio), Ciencias Naturales y Matemáticas; esto no sorprendió a los investigadores pues para acceder al contenido de la escuela es necesario el dominio del lenguaje escrito, lo cual es un foco de alarma para los educadores e investigadores relacionados con las personas sordas, pues diversos estudios han puesto de manifiesto que estos alumnos presentan múltiples dificultades al momento de adquirir habilidades de lecto-escritura (Asensio 1989; Conrad 1979; Lichtenstein, 1998; Marschark y Harrys, 1996; Musselman, 2000; Perfetti y Sandak, 2000; Soriano, Pérez y Domínguez, 2006). Aunque también es importante señalar la existencia de factores que mejoran considerablemente este pronóstico, como lo son: la utilización sistemática y a temprana edad de la Palabra Complementada (Alegría, 2003; Alegría y Domínguez, 2009; Leybaert, Colin y LaSasso, 2010). Otro aspecto es la utilización de implantes cocleares, especialmente cuando la 
intervención ha sido realizada tempranamente (Archbold et al., 2008); Marschark, Rhoten y Fabish, 2007; Nicholas y Geers, 2008; Spencer y Marschark, 2010). Las diferencias individuales muestran que si se controlan los factores lingüísticos (el vocabulario y la sintaxis), la fonología aparece como el determinante más importante de las habilidades de lectura (Alegría, 2003; Leybaert, 1993; Musselman, 2000; Perfetti y Sandak, 2000). Aunque en contraparte, Mayberry, Giudice y Lieberman (2010) plantean que la conciencia fonológica ha sido sobreestimada al momento de dar explicación a las dificultades lectoras, en su lugar proponen centrar la atención en desarrollar mayor competencia en el lenguaje de signos como base del desarrollo de la competencia en la lectura.

Los cursos educativos para sordos usualmente ponen énfasis en cinco características principales de la cultura sorda: el lenguaje, normas de comportamiento, valores/creencias, tradiciones y posesiones (Paz y Salamanca, 2009). En esta última se focaliza el lado material, pues la cultura sorda no tiene un lado inmaterial de la cultura como son la comida, vestido o música que suele compartir una cultura. Desafortunadamente un componente crítico de las posesiones culturales de los sordos, como lo es el arte es subestimado y poco investigado (Paz y Salamanca, 2006), a pesar de que según Muñoz y López-Aymes (2017, p. 2), "Una de las características más identificadas en los sujetos sordos, es el talento en las artes plásticas".

En 1989 el término Deaf View/Image Art (De’VIA) fue acuñado después de que nueve artistas (Dr. Betty G. Miller, Dr. Paul Johnston, Dr. Deborah M. Sonnnstrahl, Chuck Baird, Guy Wonder, Alex Wilhite, Sandi Inches Vasnick, Nancy Creighton y Lai-Yok Ho) discutieran para diferenciar el arte hecho por un sordo y el arte con la experiencia sorda como temática, Betty G. Miller es considerada la madre de las siglas De’VIA. Como lo indica Pérez López (2012), el colectivo sordo tiene características específicas que facilitan establecer el arte como referente al momento de establecer relaciones entre las personas y el patrimonio de ambas culturas (oyente y no oyente), por ello esta autora propone la educación patrimonial a través de la creación artística como medio de potenciar los recursos de las personas sordas para adquirir conceptos históricos, culturales y sociales.

Intervenciones a través del arte en niños con discapacidad han reportado (con sus limitaciones metodológicas) una mejora en el comportamiento social, autoconfianza y expresividad (Marschark y Harrys, 1996). Aunque dentro de sus comentarios finales, hacen énfasis al igual que la OMS $(2001,2011)$ en la necesidad de instrumentos más precisos para la medición de los cambios en el comportamiento debido a las intervenciones. Pero autores como Marschark y Harrys (1996), plantean las problemáticas de la forma contra el contenido, terapia contra lo artístico, la instrucción contra la espontaneidad; señalando que los profesionales del arte tienden a buscar el desarrollo técnico/estético dejando de lado los objetivos de desarrollo específicos de los sujetos a intervenir, para lo cual las planeaciones de clase son de utilidad.

En el estudio de Muñoz y López-Aymes (2017), se evidenció que los padres oyentes de niños sordos que muestran aptitudes sobresalientes en las artes plásticas, se centran en las dificultades y características culturalmente asociadas a la sordera; dejando de lado las potencialidades de desarrollo intrínsecas de su talento, en la mayoría de los casos, no reconocido por ellos, sino que fue descubierto por un maestro de esta área o normalista. Dentro de las recomendaciones de este estudio, están el realizar investigaciones sobre la población sorda proveniente de una familia de oyentes. 
En primera instancia, varios autores concuerdan en que no se debe ver al niño sordo como un niño normal que no escucha, pues los sordos y oyentes tienen diferentes conocimientos, trasfondos, experiencias y estrategias de aprendizaje. Los retos académicos de los sordos están relacionados con diferencias en la comprensión del lenguaje, la cognición y estrategias de aprendizaje (Agurto, 2012; Segura, 2002), recalcando que las diferencias no son deficiencias, estas pueden ser fortalezas, que igualmente suman a la diversidad del aula.

A través de la realización de diversos estudios de caso, múltiples autores han llegado a la conclusión de que el uso de diferentes lenguas tanto en señas como habladas es algo presente en la cotidianeidad del niño, por lo que necesitan pedagogías que respondan a este complejo contexto, por ello proponen que la enseñanza se haga desde una perspectiva multilingüe (Agurto, 2012; Swanwick, 2015); individualizada (Agurto, 2012; Beltrán, 2016). La metodología pedagógica más recurrida en las investigaciones consultadas fue la constructivista (Segura, 2002). Diversos autores también han remarcado la importancia del uso del diario de campo cuando el objetivo es analizar el efecto de un tratamiento sobre el desarrollo del niño con algún tipo de discapacidad (Beltrán, 2016) También es indispensable favorecer la observación y descubrimiento de su entorno (Segura, 2002). Otros trabajos también hacen hincapié en la importancia de que los alumnos expongan sus trabajos, lo cual apoya a su autoestima, autorreconocimiento y creación de una identidad ante otras personas; les ayuda a salir de sí mismos y volverse parte del entorno (Beltrán, 2016). Todo lo anterior enfocado en lograr que el niño sordo adquiera y se integra a la cultura sorda, aunque esto se logra usualmente en los casos de niños sordos hijos de padres sordos; sin embargo, también puede lograrse en hijos de padres oyentes siempre y cuando el niño pueda crear vínculos sociales con grupos de sordos que posean un principio de identidad social, en palabras de Melgar y Moctezuma (2010) "de otra forma, será un oyente-discapacitado y no un sordo funcional” (p. 7).

La enseñanza bicultural que presupone la preparación de un niño para integrarse a comunidades tanto oyentes como sordas, plantea una problemática: asegurar que el capacitador, maestro o interventor sea verdaderamente apto y capaz de transmitir ambas culturas, lo cual según Melgar y Moctezuma (2010) no es posible si no se es parte de dichas culturas, un agente partícipe de ellas.

La evaluación psicopedagógica del alumnado con discapacidad, debe hacerse sobre un
análisis profundo y riguroso de sus características personales y de contexto, de sus
necesidades educativas y de propuestas de intervención. Se debe convertir la evaluación
y diagnóstico, en un punto de partida de la intervención psicopedagógica, persiguiendo
objetivos de desarrollo curricular y académico, pero con fines de desarrollo personal y
social. (Parra y Luque-Rojas, 2013, p. 68)

Diversos autores concuerdan en que, debido a las características específicas de los niños sordos, estos presentan dificultades con las instrucciones de un examen estándar con referencia a los aspectos a evaluar (Jiménez-Torres y López, 2003; Luque y Romero, 2002). Parra y Luque-Rojas (2013) establecen que el estudio audiológico nos indica el grado de pérdida auditiva para poder establecer su posible influencia sobre el desarrollo personal y social.

En el presente estudio no se realiza una medición de este tipo, debido a que los sujetos de la investigación tienen ya identificado su nivel de audición; por motivos de recursos económicos, humanos y de tiempo, sólo se realizó el registro del nivel audiológico de los niños. Dada la importancia que marca la literatura en una evaluación del proceso y no de 
los productos mediante un diario de campo se decidió utilizar una rúbrica basada en la propuesta de Beltrán (2016), que se centra en la expresión, involucramiento y realización de las actividades por parte del niño.

\section{Método}

Se utilizó un diseño de tipo preexperimental con preprueba y posprueba con un solo grupo, su grado de control fue mínimo al no seleccionarse un grupo de control, ni haber elegido aleatoriamente a los participantes. El diseño fue transversal con un solo corte en el tiempo. La confiabilidad de la investigación viene dada por la comparación de las observaciones de las mismas variables a través de métodos e instrumentos de carácter cualitativo. El diagrama del diseño de investigación propuesto es el siguiente: O X O. Los resultados de la esta investigación son tanto cuantitativos como cualitativos.

En este estudio participaron siete niños sordos en edades de 6 a 12 años que presentaban sordera o debilidad auditiva en cualquier grado y usaban el lenguaje de señas mexicano al menos en un nivel básico, quienes probaran el tratamiento experimental contando con el consentimiento informado tanto de los niños, como de sus padres y maestros. Al mismo tiempo los padres de los niños participantes fungieron como informantes del efecto del tratamiento experimental (o falta de este) en sus hijos, firmando para ello una forma de consentimiento informado individual. Todos los participantes fueron residentes del estado de Veracruz. Cabe mencionar que en todas las sesiones estuvo presente al menos un maestro de la institución educativa receptora.

Los datos se recabaron a través de tres instrumentos, aplicados a los padres o tutores y a los niños participantes:

a) Entrevista semiestructurada con el padre o tutor del participante: diseñado para los padres, con él se recaban los datos geoestadísticos como sexo, edad y nivel de pérdida auditiva de los niños participantes, además de medir la variable Capacidad de interacción social, entendida como: la capacidad de interactuar y establecer relaciones participando y colaborando en actividades grupales, actividad que es condicionante de la aparición de la función simbólica de la conciencia y, por tanto, de las funciones psíquicas superiores. Este instrumento incluye una sección de 15 preguntas con escala de Likert del 1 al 5, para calificar la frecuencia con la que el padre o tutor percibía que su hijo presentaba ciertas actitudes o ejercía acciones relacionadas con la capacidad de interacción social (donde $1=$ casi nunca, $2=$ pocas veces, $3=$ algunas veces, $4=$ muy a menudo y $5=$ casi siempre). $\mathrm{La}$ entrevista ayudó a formar una imagen del estado inicial del participante y sus necesidades específicas. Después de finalizar la intervención, se realizó otra breve entrevista semiestructurada de manera individual con los padres de familia para realizar un registro de sus percepciones sobre la clase y los efectos percibidos en sus hijos.

b) Test de vocabulario en imágenes Tevi-R: de Echeverría, Herrera y Segure (1982), este instrumento midió la variable Comprensión del vocabulario y se aplicó a los niños participantes en presencia de un maestro de la institución receptora. Este instrumento da una escala categórica sobre en qué nivel de comprensión de vocabulario está el niño con relación a su edad. Este test está diseñado para evaluar a sujetos entre 2,5 y 17 años de edad. Está conformado por 116 láminas con cuatro imágenes a color en cada una que representan sustantivos, adjetivos y verbos; lista de estímulos de 116 elementos (palabras a identificar en las láminas) con forma A y B; una hoja de respuestas. Para dar inicio al 
desarrollo del instrumento la persona evaluadora explica las instrucciones, y luego comienza a mencionar los términos en la lista de estímulos uno por uno dando tiempo para respuestas, posteriormente el niño debe señalar en la lámina de ilustraciones la que mejor ejemplifique dicho término, el examinador o auxiliar consigna cada respuesta en la hoja de respuestas del Test de Vocabulario en Imágenes, para posteriormente extraer los resultados obtenidos.

Las láminas van cambiando de contener sustantivos simples (casa, perro, pájaro) a adjetivos y constructos más complejos (perezoso, esperanza, horror). La lámina inicial va en concordancia con la edad del niño (2 a 4 años, lámina 1; 5 a 6 años, lámina 15; 7 a 11 años, lámina 30 y 12 años en adelante desde la lámina 50), cuando el alumno presente seis errores dentro de ocho láminas consecutivas la aplicación debe terminar, por último, este test cuenta con una tabla de normas para su interpretación. Dicha interpretación se da en las siguientes categorías: mayor a 65 , sobresaliente; 55 a 64 , muy bueno; 45 a 54 , normal; 35 a 44, retraso leve y menor a 35, retraso grave. Para este estudio, el constructo Comprensión del vocabulario se entendió como: el proceso a través del cual se elabora un significado en su interacción con los símbolos (Anderson y Pearson, 1984). Así determinaremos si el niño puede hacer una relación exitosa de los sustantivos con sus representaciones gráficas, usamos este instrumento para poder verificar si hay un cambio en el nivel de comprensión del vocabulario en las observaciones antes y después de la intervención.

c) Instrumento de registro de indicadores evolutivos en dibujos libres infantiles: adaptación del Instrumento Expresión Plástica: Proceso, Comunicación, Representación de Beltrán (2016), para registrar el desarrollo de la variable Habilidades gráficoexpresivas al analizar las características de los trabajos realizados durante la primera y última sesión. Entendiendo las Habilidades gráfico-expresivas, según lo postula LópezBosch (2000), como las habilidades para expresar y desarrollar en el plano visual los procesos de simbolización, los procesos de desarrollo expresivo y los de desarrollo creativo.

En este diario de campo se hace patente la presencia en los trabajos de indicios de expresión del universo interno del niño y observación de avances en su desarrollo técnicoexpresivo con calificaciones del estado del trabajo mostrado en clase medido en una escala Likert de 5 puntos donde $1=$ deficiente, $2=$ bajo, $3=$ regular, $4=$ bueno y $5=$ excelente; calificando 6 ítems: i) Expresa vivencias y situaciones a través de la producción plástica, ii) Expresa emociones y sentimientos a través de la producción plástica, iii) Expresa fantasías propias a través de la producción plástica, iv) Muestra creatividad en el uso de los materiales y técnicas, v) Experimentación con el lenguaje plástico (línea, forma, color, textura, espacio y punto), vi) Participación activa en realizaciones colectivas. El instrumento también contiene un séptimo ítem para marcar la etapa de desarrollo pictográfico del participante, tomando como base la propuesta de Lowenfeld (1961), donde 1 = Garabato, 2 = Pre-esquemático, $3=$ Esquemático, $4=$ Realismo y $5=$ Seudonaturalismo. Finalizando con una sección abierta para el registro de observaciones. Para seleccionar en qué etapa se encuentra cada dibujo, se toma como base la descripción mostrada en el cuadro 1 propuesta por Lowenfeld (1961). 
Cuadro 1. Descripción de las etapas del desarrollo pictográfico infantil

\begin{tabular}{|c|c|c|c|c|}
\hline ETAPA & CARACT. & $\begin{array}{c}\text { REPR. DE LA } \\
\text { FIGURA HUMANA }\end{array}$ & $\begin{array}{l}\text { REPR. DEL } \\
\text { ESPACIO }\end{array}$ & $\begin{array}{c}\text { USO } \\
\text { COLOR }\end{array}$ \\
\hline $\begin{array}{l}\text { Garabato } \\
\text { (2 a } 4 \text { años) }\end{array}$ & $\begin{array}{l}\text { Sin control } \\
\text { motor, } \\
\text { desordenada. }\end{array}$ & $\begin{array}{l}\text { Sólo } \\
\text { imaginativamente }\end{array}$ & $\begin{array}{l}\text { Sólo } \\
\text { imaginativamente }\end{array}$ & $\begin{array}{l}\text { Sin uno } \\
\text { consciente } \\
\text { para } \\
\text { representar, } \\
\text { se usa para } \\
\text { distinguir } \\
\text { entre } \\
\text { garabatos }\end{array}$ \\
\hline $\begin{array}{l}\text { Preesquemática } \\
\text { (4 a } 7 \text { años) }\end{array}$ & $\begin{array}{l}\text { Descubre } \\
\text { relaciones } \\
\text { entre la } \\
\text { representación } \\
\text { y lo } \\
\text { representado }\end{array}$ & $\begin{array}{l}\text { Búsqueda de } \\
\text { concepto, } \\
\text { constante } \\
\text { creación y cambio } \\
\text { de símbolos }\end{array}$ & $\begin{array}{l}\text { No hay orden en } \\
\text { el espacio, las } \\
\text { relaciones } \\
\text { dependen del } \\
\text { significado } \\
\text { emocional }\end{array}$ & $\begin{array}{l}\text { Uso } \\
\text { emocional, no } \\
\text { relacionado } \\
\text { con la } \\
\text { realidad }\end{array}$ \\
\hline $\begin{array}{l}\text { Esquemática } \\
\text { ( } 7 \text { a } 9 \text { años) }\end{array}$ & $\begin{array}{l}\text { Creación de } \\
\text { esquemas } \\
\text { mediante el } \\
\text { repetido } \\
\text { descubrimiento } \\
\text { de conceptos }\end{array}$ & $\begin{array}{l}\text { Conceptos } \\
\text { definidos, } \\
\text { dependiendo del } \\
\text { conocimiento y } \\
\text { características de } \\
\text { la personalidad }\end{array}$ & $\begin{array}{l}\text { Uso de la línea de } \\
\text { base, } \\
\text { descubrimiento } \\
\text { de que se forma } \\
\text { parte del } \\
\text { ambiente, } \\
\text { representación } \\
\text { subjetiva del } \\
\text { espacio, concepto } \\
\text { del espacio- } \\
\text { tiempo }\end{array}$ & $\begin{array}{l}\text { Relación } \\
\text { definida entre } \\
\text { el color y el } \\
\text { objeto, } \\
\text { formación de } \\
\text { un esquema } \\
\text { de color por } \\
\text { repetición }\end{array}$ \\
\hline $\begin{array}{l}\text { Realismo } \\
\text { (9 a } 11 \text { años) }\end{array}$ & $\begin{array}{l}\text { Mayor } \\
\text { conciencia del } \\
\text { yo. } \\
\text { Alejamiento } \\
\text { del esquema. } \\
\text { Alejamiento de } \\
\text { las líneas } \\
\text { geométricas. } \\
\text { Cuidado en las } \\
\text { proporciones. }\end{array}$ & $\begin{array}{l}\text { Acentuación de } \\
\text { las ropas. } \\
\text { Diferenciación de } \\
\text { niñas y varones. } \\
\text { Tendencia hacia } \\
\text { líneas realistas. } \\
\text { Alejamiento de } \\
\text { las } \\
\text { representaciones } \\
\text { esquemáticas }\end{array}$ & $\begin{array}{l}\text { Superposición, } \\
\text { descubrimiento } \\
\text { del plano. } \\
\text { Necesidad de } \\
\text { expresiones } \\
\text { tridimensionales. } \\
\text { Disminución del } \\
\text { tamaño de los } \\
\text { objetos distantes. } \\
\text { La línea de } \\
\text { horizonte }\end{array}$ & $\begin{array}{l}\text { Experiencias } \\
\text { subjetivas de } \\
\text { color con } \\
\text { objetos de } \\
\text { significación } \\
\text { emocional. }\end{array}$ \\
\hline $\begin{array}{l}\text { Pseudonaturalismo } \\
\text { (11 a } 13 \text { años) }\end{array}$ & $\begin{array}{l}\text { Conciencia } \\
\text { crítica hacia el } \\
\text { medio }\end{array}$ & $\begin{array}{l}\text { Acentúa luces y } \\
\text { sombras, } \\
\text { impresiones } \\
\text { momentáneas }\end{array}$ & $\begin{array}{l}\text { Uso de la } \\
\text { perspectiva, } \\
\text { cualidades } \\
\text { tridimensionales }\end{array}$ & $\begin{array}{l}\text { Cualidades } \\
\text { cambiantes } \\
\text { del color en } \\
\text { la naturaleza } \\
\text { respecto a la } \\
\text { distancia y } \\
\text { estado de } \\
\text { ánimo }\end{array}$ \\
\hline
\end{tabular}

Fuente: Elaboración propia a partir de Lowenfeld, (1961, pp. 564-566).

Se explicó a los participantes en qué consiste el taller experimental y cuáles son los posibles beneficios para ellos al aceptar participar, se procedió a la aplicación de la encuesta para los padres y el instrumento para medir el vocabulario a los niños. Los menores estuvieron en todo momento acompañados de sus padres o tutores. Se formó un grupo de niños por conveniencia, con siete integrantes, en edades de 7 a 12 años; todos residentes del estado de Veracruz. 
La investigación se realizó durante los meses de febrero a junio del 2018. Las actividades de planteamiento, justificación teórica, análisis de datos y conclusiones se realizaron durante la intervención y recolección de datos realizados en la Ciudad de Xalapa, ubicada en el Estado de Veracruz, México. La intervención constó de ocho sesiones impartidas dos veces por semana cada una con duración de dos horas en el lapso de un mes. Se llevó un registro del desarrollo técnico-expresivo en el dibujo siguiendo los protocolos establecidos. Se realizaron las entrevistas a los padres y mediciones a los niños post intervención.

En cuanto al análisis del contenido de las entrevistas a padres, se asignaron códigos relacionados con colores para identificar temas constantes en las trascripciones, se identificaron frases similares y secuencias comunes. Se elaboraron las primeras reflexiones y notas analíticas, para posteriormente elaborar observaciones y proposiciones de acuerdo a la base de datos. Se compararon estas propuestas o generalizaciones con el conocimiento y teorías previas en la materia.

Se analizó la información estadística de los participantes, la escala Likert de la entrevista a padres y los resultados numéricos del Instrumento de registro de indicadores evolutivos en dibujos libres infantiles mediante análisis descriptivos, comparando los de la preprueba y la posprueba; además se realizó una prueba de correlación en los resultados obtenidos usando el coeficiente de correlación de Pearson.

Desde la primera sesión se instruye a los participantes para que marquen con su nombre todos sus trabajos en la parte trasera de los mismos. En todas las sesiones se hace un glosario con los dibujos de una o dos señas desconocidas o poco usadas por los participantes junto a su expresión escrita, esto en la primera mitad de la sesión, promoviendo su uso en la última mitad de esta. Para posibilitar la futura replicación del estudio, en el cuadro 2 se describe de manera breve la guía de actividades diseñada para la intervención, cabe señalar que el interventor debe tener los conocimientos básicos en LSM que le permitan dar instrucciones básicas a los participantes.

Cuadro 2. Guía de actividades para favorecer el desarrollo técnico-expresivo de niños sordos

\begin{tabular}{|c|c|c|}
\hline SESIÓN & MATERIALES & DESCRIPCIÓN \\
\hline 1 & $\begin{array}{l}\text { Cartón, tijeras, } \\
\text { pintura vinílica y } \\
\text { pinceles }\end{array}$ & $\begin{array}{l}\text { Como parte del pretest al inicio de la sesión se pide a los } \\
\text { participantes que de forma libre representen un árbol de cualquier } \\
\text { tamaño y forma usando pintura vinílica. Posteriormente se hará } \\
\text { una introducción al grupo y presentación de los niños entre sí en } \\
\text { caso de no conocerse, repasando las señas de cada uno. En seguida } \\
\text { se da una breve introducción al tema de las emociones contando } \\
\text { alguna anécdota sencilla, se invita a los estudiantes a compartir un } \\
\text { momento en el que hayan experimentado un sentimiento muy } \\
\text { fuerte, después el grupo hace una lista de emociones. De esta lista, } \\
\text { cada uno escoge una emoción de la que hará una máscara. Al } \\
\text { finalizar cada uno actuará la emoción usando su máscara, se } \\
\text { fomenta la discusión sobre cómo deberían de reaccionar ante una } \\
\text { persona que presenta dicha emoción. El maestro tomará fotos de } \\
\text { cada estudiante actuando la emoción con y sin las máscaras Estas } \\
\text { máscaras se quedan en el salón. }\end{array}$ \\
\hline 2 & $\begin{array}{l}\text { Las fotos de la } \\
\text { actividad anterior } \\
\text { en formato } \\
\text { impreso, cartas } \\
\text { describiendo }\end{array}$ & $\begin{array}{l}\text { El estudiante escogerá una carta y expresará la emoción descrita } \\
\text { en la carta, si no puede comprenderla puede pedir ayuda a sus } \\
\text { compañeros, sólo si el grupo no puede completar este paso por sí } \\
\text { solo es que intervendrá el maestro. Las tarjetas corresponderán a } \\
\text { las emociones tratadas en la actividad pasada y cada alumno debe }\end{array}$ \\
\hline
\end{tabular}




\begin{tabular}{|c|c|c|}
\hline & $\begin{array}{l}\text { emociones, } \\
\text { Cartulina grande, } \\
\text { Pegamento, } \\
\text { tijeras, pinturas } \\
\text { vinílicas, pinceles. }\end{array}$ & $\begin{array}{l}\text { identificar a cuál máscara pertenece la descripción de su tarjeta. El } \\
\text { maestro pondrá los nombres de las emociones en la cartulina, los } \\
\text { alumnos deben colocar sus fotos en el nombre de la emoción } \\
\text { correspondiente, deben terminar el cartel de emociones con } \\
\text { dibujos que representen situaciones donde se pueda dar cada } \\
\text { emoción }\end{array}$ \\
\hline 3 & $\begin{array}{l}\text { Fábula sobre } \\
\text { colores, } \\
\text { sugerencias: El } \\
\text { monstruo de } \\
\text { colores de Joanna } \\
\text { Sanz, Mis días } \\
\text { coloridos de Dr. } \\
\text { Seuss. } \\
\text { Papel, pintura } \\
\text { vinílica y pinceles. }\end{array}$ & $\begin{array}{l}\text { El maestro leerá el libro a los estudiantes. Comenzará la discusión } \\
\text { sobre cómo se usan los colores en la historia para representar } \\
\text { sentimientos. Se les pide a los estudiantes que cierren los ojos e } \\
\text { imaginen un momento muy feliz en sus vidas. Los estudiantes } \\
\text { deben crear sus propias pinturas para representar los sentimientos } \\
\text { que les evoque su recuerdo. El maestro recalcará que no hay una } \\
\text { forma correcta o incorrecta de expresar los sentimientos, que lo } \\
\text { importante es que usen su creatividad, pero puede hacer } \\
\text { sugerencias si es necesario. Es importante felicitarlos por sus } \\
\text { logros. Se hace una cartulina en la que se colocan los dibujos ya } \\
\text { secos para que sean apreciados por los padres o tutores y se } \\
\text { impulsa el intercambio de ideas entre ellos y los participantes } \\
\text { sobre lo expresado mediante sus trabajos hasta este punto. }\end{array}$ \\
\hline 4 & $\begin{array}{l}\text { Cualquier tipo de } \\
\text { material puede ser } \\
\text { usado en este reto, } \\
\text { entre más } \\
\text { variedad mejor, } \\
\text { debe tomarse en } \\
\text { cuenta que el reto } \\
\text { es construir algo, } \\
\text { así que es de } \\
\text { ayuda que los } \\
\text { materiales tengan } \\
\text { posibilidad de ser } \\
\text { ensamblados de } \\
\text { forma accesible } \\
\text { para los alumnos. }\end{array}$ & $\begin{array}{l}\text { El maestro proveerá de diversos materiales a los estudiantes y } \\
\text { dará la indicación de que deben trabajar juntos para construir } \\
\text { algo, siempre que sea necesario debe recordarles que el trabajo es } \\
\text { en equipo, pero no interferir de otro modo o dar sugerencias de lo } \\
\text { que deben hacer a menos que sea para cuidar el bienestar de los } \\
\text { participantes. Se les debe recordar que es necesario discutir y que } \\
\text { todos estén de acuerdo en qué van a construir y cómo lo harán, } \\
\text { además de que deben intentar resolver los problemas que surjan } \\
\text { ellos mismos, aunque pueden pedir ayuda al maestro si ellos ya } \\
\text { han agotado sus opciones. Ya que en este intercambio de ideas } \\
\text { puede emplearse mucho tiempo debe poder considerarse seguir } \\
\text { esta actividad en una sesión diferente. }\end{array}$ \\
\hline 5 & $\begin{array}{l}\text { Papel, lápiz, } \\
\text { sacapuntas y } \\
\text { goma }\end{array}$ & $\begin{array}{l}\text { Se da una breve explicación sobre diferentes tipos de ojos, narices } \\
\text { y labios y cómo dibujarlos, la explicación se acompaña de } \\
\text { ejemplos dados a gran escala al frente del salón. Los participantes } \\
\text { se organizan en parejas, frente a frente para realizar un dibujo del } \\
\text { rostro de su compañero, posteriormente todos los trabajos se } \\
\text { revuelven en una pila, se sacan al azar y los participantes deben } \\
\text { adivinar a cuál de sus compañeros se representa indicando su } \\
\text { respuesta con el nombre en señas correspondiente. El autor } \\
\text { corrobora la respuesta y pasa al frente junto a su modelo, allí } \\
\text { deben compartir al grupo algo que le guste de su modelo y algo } \\
\text { que le guste de su retrato, concluyen sacando el siguiente trabajo. }\end{array}$ \\
\hline 6 & $\begin{array}{l}\text { Papel blanco, } \\
\text { acuarelas, } \\
\text { recipientes con } \\
\text { agua, trapos } \\
\text { absorbentes y } \\
\text { pinceles }\end{array}$ & $\begin{array}{l}\text { Al frente del grupo y en gran formato, el interventor da una } \\
\text { explicación sobre los cuidados especiales al trabajar con acuarela } \\
\text { (sobre la fuerza en el pincel, el uso del agua y trapo para evitar } \\
\text { mezclar colores por accidente), además de ejemplos sobre las } \\
\text { posibilidades para las transparencias y mezcla de colores en el } \\
\text { lienzo de este material, esto mientras comparte una fábula sobre él } \\
\text { y su familia. Los participantes ahora deberán crear una fábula } \\
\text { sobre ellos y su propia familia, posteriormente pasan al frente, } \\
\text { donde sus compañeros tratan de adivinar su historia, el autor va } \\
\text { dando retroalimentación y de ser necesario cuenta la historia por } \\
\text { sí mismo o con ayuda del interventor. }\end{array}$ \\
\hline 7 & $\begin{array}{l}\text { Papel en gran } \\
\text { formato (kraft o } \\
\text { cartulina), }\end{array}$ & $\begin{array}{l}\text { Los participantes formarán grupos de } 3 \text { a } 5 \text { personas } \\
\text { (dependiendo del tamaño del grupo, esto se deja a criterio del } \\
\text { interventor). El instructor pregunta por los lugares en los que }\end{array}$ \\
\hline
\end{tabular}




\begin{tabular}{|c|c|c|}
\hline & $\begin{array}{l}\text { acuarelas, pintura } \\
\text { vinílica, } \\
\text { recipientes con } \\
\text { agua, trapos } \\
\text { absorbentes y } \\
\text { pinceles }\end{array}$ & $\begin{array}{l}\text { pasan tiempo los participantes, va anotando lo mencionado en un } \\
\text { pizarrón, de no haber aportaciones da un par de ideas, las palabras } \\
\text { van al glosario junto con el dibujo de lo expresado y su versión } \\
\text { escrita. En gran formato y al frente del salón el maestro va } \\
\text { ejemplificando cómo podrían pintarse algunas cosas de las } \\
\text { mencionadas por los participantes, se asigna un lugar a cada } \\
\text { equipo y se entrega un trozo grande de papel, deben hacer una } \\
\text { representación de dicho lugar con el mayor número de cosas, } \\
\text { personas y animales que se encuentren usualmente en él. Al } \\
\text { finalizar todos los equipos deben describir con LSM lo contenido } \\
\text { en sus murales ante el grupo. Como requerimiento para la } \\
\text { posprueba, cada participante debe representar un árbol de } \\
\text { cualquier tamaño y forma usando pintura vinílica. }\end{array}$ \\
\hline 8 & $\begin{array}{l}\text { Masking tape y } \\
\text { estambre }\end{array}$ & $\begin{array}{l}\text { Se realiza el cierre de actividades montando una exposición con } \\
\text { los trabajos de los participantes, dicha exposición puede ser con la } \\
\text { asistencia de padres de familia o sus compañeros oyentes, } \\
\text { dependiendo de las circunstancias; procurando su acomodo por } \\
\text { autor y número de sesión, los participantes expresarán en LSM sus } \\
\text { percepciones del curso, las artes plásticas y descripción de su } \\
\text { trabajo final auxiliado por un intérprete para el público oyente. }\end{array}$ \\
\hline
\end{tabular}

Fuente: Elaboración propia.

\section{Resultados}

En cuanto a la distribución por sexo en los participantes, un $57,1 \%(\mathrm{n}=4)$ fueron mujeres y el 42,9\% ( $\mathrm{n}=3)$ hombres. Del total de participantes: sólo el 42,9\% (n = 3) tenía al menos un padre o tutor que comprendiera el lenguaje de señas mexicano; el $57,1 \%(\mathrm{n}=4)$ tenía padres que se autocalificaron como de bajos recursos durante la entrevista semiestructurada inicial y el $28,5 \%(n=2)$ no sabían leer o escribir, fue en estos dos últimos participantes mencionados, donde se encontró que la expresión a través de las artes plásticas ya se había instituido de forma natural para subsanar la carencia de otras formas de comunicación, aunque se encontraba en un nivel esquemático de acuerdo a la descripción del mismo padre o tutor, nivel inferior al esperado para el rango de edad y nivel escolar de estos participantes según Beltrán (2016) o Piaget (1937).

En los casos donde el padre o tutor se percibía como incapaz de comunicarse con su hijo(a) con la Lengua de Señas Mexicana (LSM), la comunicación se llevaba a cabo conjuntando diversas técnicas: i) de manera escrita (en los casos donde tanto ellos como los niños sabían leer y escribir); ii) a través de dibujos (yendo desde el garabato hasta lo esquemático) y iii) con señas, miradas, movimientos de cabeza y otros gestos corporales.

En cuanto a su actitud en el ámbito escolar, un 42,9\% $(\mathrm{n}=3)$ de los padres o tutores, expresó que sus hijos o tutorados mostraban poca motivación: "es bien distraído y no le hace caso a nadie", "hay veces que no quiere venir, y hasta de malas se pone".

\subsection{Capacidad de interacción social}

La interpretación cuantitativa de este test, da las siguientes categorías: mayor que 65, sobresaliente; 55 a 64 , muy bueno; 45 a 54 , normal; 35 a 44, retraso leve y menor que 35 , retraso grave. Resalta la desaparición de casos categorizados como con retraso leve, siendo este porcentaje el que avanzó a normal en la posprueba y aumentando de un 57,14\% a $85,71 \%$ la incidencia en sobresaliente al término de la intervención. Lo que podría indicar que hubo una mejora en la comprensión del vocabulario durante la implementación del tratamiento experimental. 
Por métodos cualitativos (Instrumento para el registro de desarrollo técnico-expresivo del infante), se encontró la percepción del tratamiento experimental (clase de dibujo, como se llamaba en el contexto de la escuela receptora) como un aliciente por parte de los niños para adquirir mayor vocabulario en LSM, además de animarlos a su uso tanto con la maestra como con el resto de sus compañeros sordos.

\subsection{Comprensión del vocabulario}

Los resultados del análisis de contenido en las entrevistas realizadas, se clasificaron en tres temas: i) Interacción y establecimiento de relaciones por parte del niño(a), ii) Participación del niño(a) en actividades colectivas, iii) Percepciones del padre o tutor sobre la clase de pintura.

Dentro de la Interacción y establecimiento de relaciones, en todas las entrevistas realizadas en la preprueba fue expresada la percepción de que los participantes tenían dificultad para comunicarse con personas que desconocían la Lengua de Señas Mexicana (LSM), prefiriendo evitar interacciones con personas ajenas a su círculo más cercano; aunque sólo un $42 \%(\mathrm{n}=3)$ dijo tener comunicación con su hijo sobre sus actividades en horario escolar. En la posprueba el $86 \%(\mathrm{n}=6)$ de los padres expresaron que sus hijos se entusiasmaban por mostrar sus creaciones pictóricas a las personas que visitan su hogar, incluyendo parientes lejanos y amigos de los padres, sin importar que el invitado no conociera la LSM. Estos mismos padres reportaron tener mayor comunicación con sus hijos sobre sus actividades en la escuela, aunque usualmente se limitaba a las actividades en el tratamiento experimental. En la preprueba el $71 \%(n=5)$ de los padres describieron explosiones emocionales en sus hijos: eran lapsos de ira, tristeza o euforia desenfrenada en los que los participantes incurrían varias veces al mes; en la posprueba cuatro de estos cinco padres mencionó una disminución de estos episodios y el padre restante refirió que la intensidad de estos había bajado.

Sobre la participación en actividades colectivas, los padres refirieron en todas las entrevistas de la preprueba que en casa no tienen problemas al realizar actividades cotidianas juntos ni participar en juegos (con sus padres, abuelos o hermanos), esta incidencia no cambió en la posprueba, pero aumentaron los comentarios sobre la integración por parte de los niños a actividades donde participaban personas que eran menos familiares para los niños, con la adecuada guía del padre o tutor.

En cuanto a las percepciones del padre o tutor sobre la clase de pintura, en la preprueba todas las aportaciones se referían a la naturaleza lúdica de la actividad, sólo el $28 \%(\mathrm{n}=2)$ percibía la actividad como una herramienta de expresión para su hijo, y el $42 \%$ (n=3) como una herramienta para promover su desarrollo; en la posprueba se mantuvo la visión de la clase de pintura como una actividad lúdica, pero en el $86 \%(n=6)$ de las entrevistas se añadió una función ligada a la expresión tanto a través de las pinturas como de la LSM, pues se mencionó que los participantes compartían con señas los procesos, significados y narraciones de sus creaciones.

\subsection{Habilidades gráfico-expresivas}

En cuanto a la parte numérica del test, se analizaron de forma cuantitativa los resultados y se compararon los datos de la preprueba y posprueba de cada ítem dando los resultados mostrados en el cuadro 3 donde se observa un aumento en las medias de todos los ítems en la posprueba. 
Con relación a la pregunta "expresa vivencias y situaciones", mientras que en la medición inicial la media se encontraba en la categoría de Bajo, al finalizar la intervención, todos los estudiantes se colocaron en las categorías de Bueno y Excelente, de tal modo que la media del grupo se ubicó en 4,5 en la medición final. Este resultado tuvo su paralelo en el análisis cualitativo, pues durante el análisis de contenido con métodos cualitativos, se encontró que al inicio del curso los participantes se mostraban reacios a plasmar partes de su realidad en sus trabajos, los participantes buscaban limitarse a duplicar imágenes del entorno inmediato (el aula o escuela) dejando fuera su hogar y familia. Conforme transcurrieron las sesiones, era constante que el maestro titular del grupo de participantes expresara haberse enterado de algún aspecto de las vivencias y situaciones concretas de los niños a través de sus trabajos en el tratamiento experimental, algunos fragmentos que dan cuenta de eso son: "no tenía idea de los problemas que traen los niños", "no sabía qué tenían, por qué se comportaban así de mal, ya sé por qué”.

Cuadro 3. Comparación de las medias de la preprueba y posprueba del instrumento de registro de desarrollo técnico-expresivo del infante

\begin{tabular}{lcc}
\hline & PRE TEST & POST TEST \\
\hline Expresa vivencias y situaciones & 2,0 & 4,5 \\
Expresa emociones y sentimientos & 2,4 & 4,7 \\
Expresa fantasías propias & 2,4 & 5,0 \\
Creatividad en el uso de los materiales y técnicas & 2,4 & 4,5 \\
Experimentación con el lenguaje plástico & 2,2 & 4,4 \\
Participación activa en realizaciones colectivas & 2,0 & 4,8 \\
Etapa del desarrollo gráfico & 2,1 & 2,7 \\
\hline
\end{tabular}

Fuente: Elaboración propia.

En cuanto al logro de expresión de emociones y sentimientos a través de la práctica artística, en la preprueba el $85,7 \%(n=6)$ se encontraba en la categoría de regular a deficiente, al finalizar la intervención el 100\% de los participantes se colocó en el rango de bueno a excelente, tal como se reflejó en las notas de campo, donde se observó que las primeras veces que se alentaba este tipo de actividades, los niños se mostraban cohibidos y renuentes a compartir sus emociones y sentimientos; a medida que transcurrió la intervención se mostraron más abiertos hasta el punto de compartir de manera más profunda estos aspectos de ellos mismos, lo cual es congruente con los resultados cuantitativos.

Dentro del ítem sobre la habilidad de comunicar fantasías propias en la obra plástica, se logró un aumento en la media de 2,4 a 5, pues al término de la intervención el 100\% de los niños logró una categorización de excelente, al finalizar la intervención, los participantes se atrevían a pensar de manera más abstracta y surrealista, las creaciones ya no se limitaban a intentar imitar su entorno y se enorgullecían de las posibilidades expresivas de sus creaciones. Sobre la creatividad en el uso de los materiales, como se observa en la figura 1, se registró un aumento en la media de este reactivo de 2,42 a 4,57 al término de la intervención, también se logró eliminar las incidencias en deficiente. 


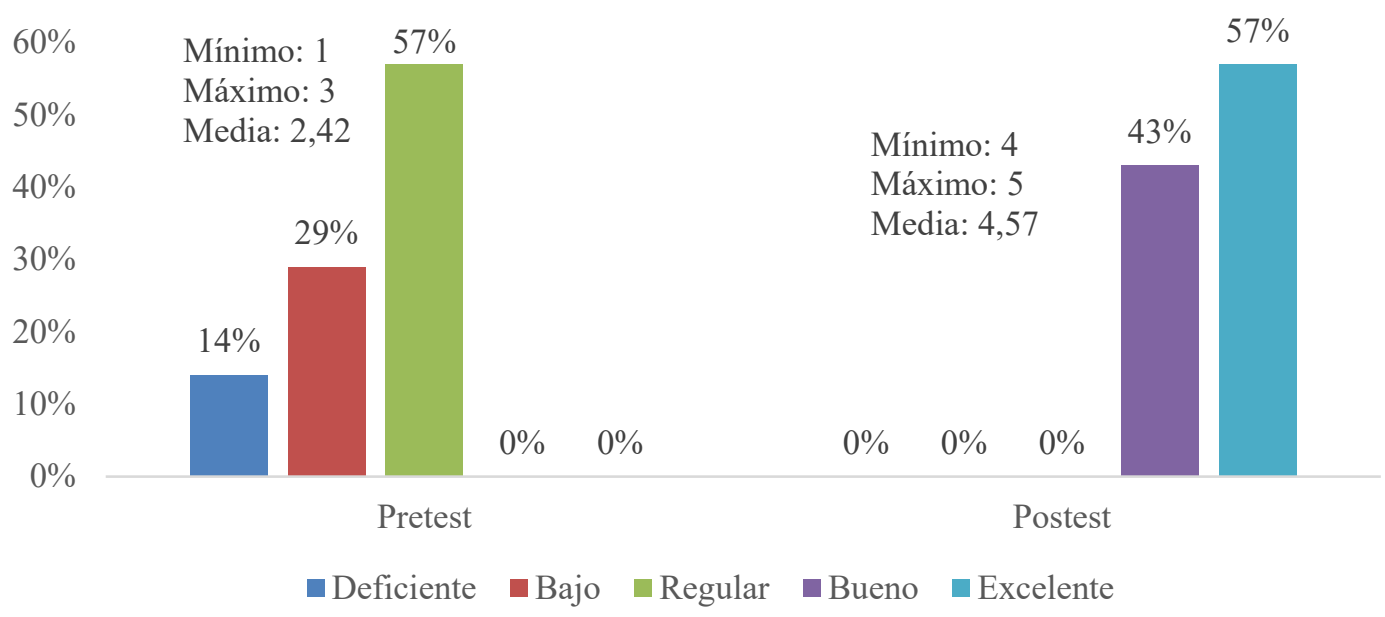

Figura 1. Creatividad en el uso de los materiales, comparativa entre pre y post test Fuente: Elaboración propia.

Sobre la experimentación con los elementos del lenguaje plástico (línea, forma, color, textura, espacio y punto), como vemos en la figura 2 , el $87 \%(\mathrm{n}=6)$ de los participantes se encontraba entre las categorías de Deficiente y Regular en la preprueba, terminando el $100 \%$ en el rango de Bueno a Excelente al finalizar el estudio. Dentro de lo registrado en el diario de campo, se observó que al inicio los participantes realizaban las actividades con el menor esfuerzo y recursos posibles, con una actitud ya observada por los maestros de la escuela receptora y descrita por ellos mismos como "cumplir por cumplir", conforme avanzaron las sesiones, aumentaron los registros en el diario de campo sobre el aumento de interés de los participantes por adquirir mayor destreza para plasmar formas, colores y espacios en sus creaciones, reflejado en el aumento en la puntuación de este ítem al momento de la posprueba.

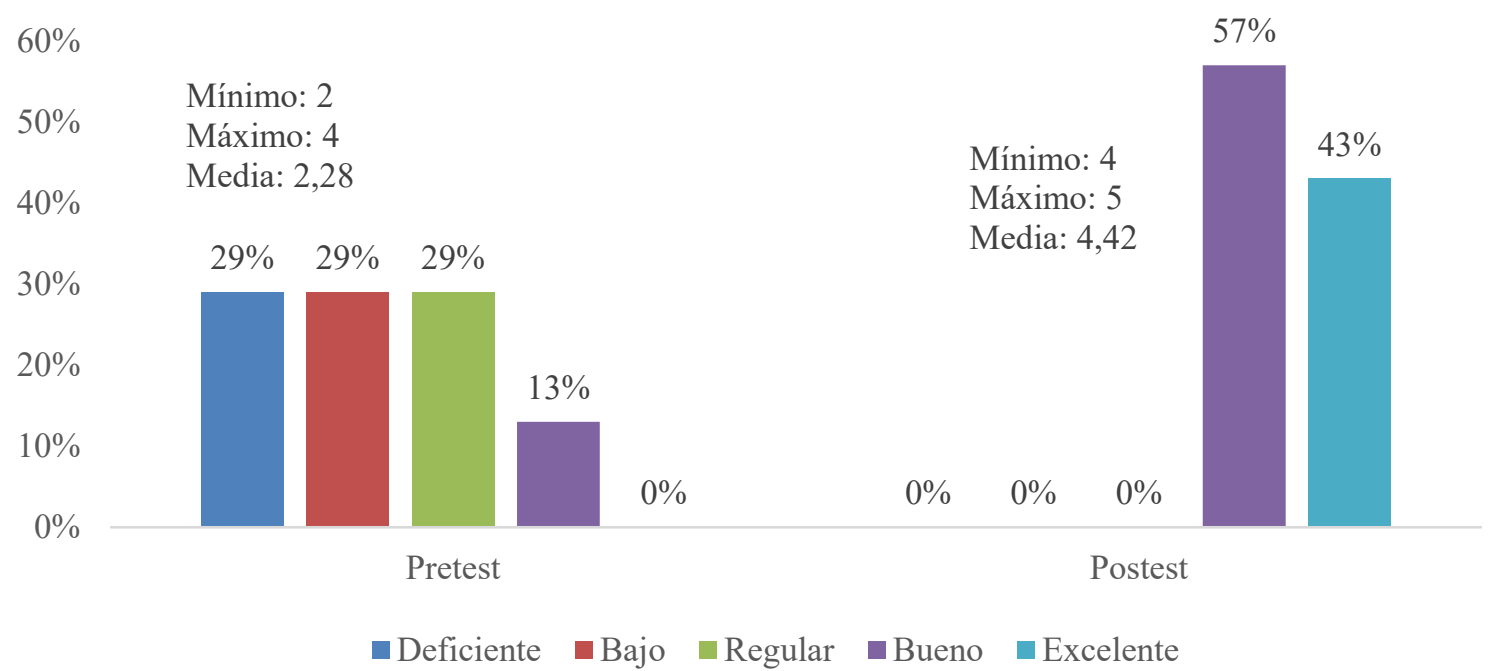

Figura 2. Experimenta con los elementos del lenguaje plástico, comparativa entre pre y post test

Fuente: Elaboración propia. 
Los resultados sobre la participación en creaciones colectivas, visualizado en la figura 3 , se elevó la media de 2 a 4,8 al término de la intervención, logrando que el $86 \%(\mathrm{n}=6)$ de los participantes concluyeran en Excelente. Al inicio de la intervención, los participantes eran reacios a trabajar en equipo, incluso a compartir material para hacer trabajos individuales, sin embargo, al momento de la posprueba los participantes pedían poder realizar las actividades en conjunto, se registró que en los trabajos colectivos se daba diálogo y búsqueda de acuerdos sobre la dirección de la obra y división de tareas.

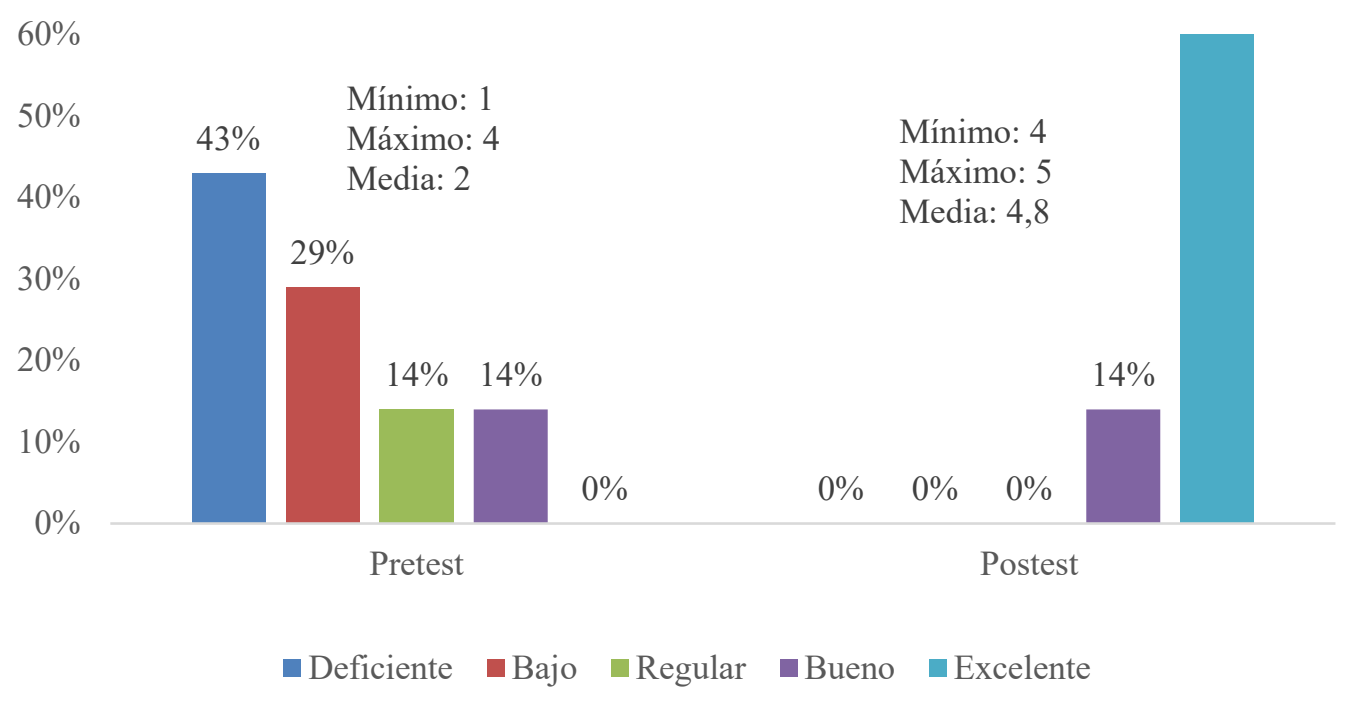

Figura 3. Participación en creaciones colectivas, comparativa entre pre y post test Fuente: Elaboración propia.

En la figura 4, se observa la comparación de dos trabajos realizados por el mismo participante, en la pre y posprueba llevadas a cabo en la sesión 1 y 7 respectivamente, así como la calificación asignada a cada trabajo. Los dos trabajos fueron hechos con el mismo material (pintura vinílica) y tratando de representar la misma idea (un árbol).

\subsection{Análisis correlacional}

Se encontraron asociaciones lineales estadísticamente significativas. Una de las más destacables fue la asociación estadísticamente significativa e inversa, entre la variable independiente sexo y las puntuaciones en los ítems de: reconocer las emociones de otros $(\rho=-0,917, p<0,05)$, responder apropiadamente a las emociones de otros $(\rho=-0,810, p$ $<0,05)$ y la medida inicial de expresar y comunicar emociones y sentimientos $(\rho=0,904$, $\mathrm{p}<0,05$ ); ítems en los cuales, la preprueba, las participantes de sexo femenino obtuvieron una media superior a sus contrapartes masculinos, lo cual tiene muchas implicaciones dada la carga cultural que en México recae en las mujeres desde pequeñas para ser empáticas y en los hombres para cerrarse a este aspecto de sus vidas.

También pudieron observarse asociaciones lineales estadísticamente significativas entre los ítems hacer nuevos amigos y los ítems de: iniciar interacciones sociales $(\rho=0,842, \mathrm{p}$ $<0,05)$, la percepción de los padres de la habilidad de los participantes de expresar emociones apropiadamente $(\rho=0,923, \mathrm{p}<0,05)$ y el ítem de Iniciar interacciones sociales $(\rho=0,842, p<0,05)$; esto apoya el enfoque de la investigación hacia el desarrollo expresivo para mejorar las habilidades expresivas del participante, se remarca la 
importancia de expresar de manera adecuada las emociones para las habilidades sociales del niño sordo al permitirle iniciar o integrarse a actividades en proceso.

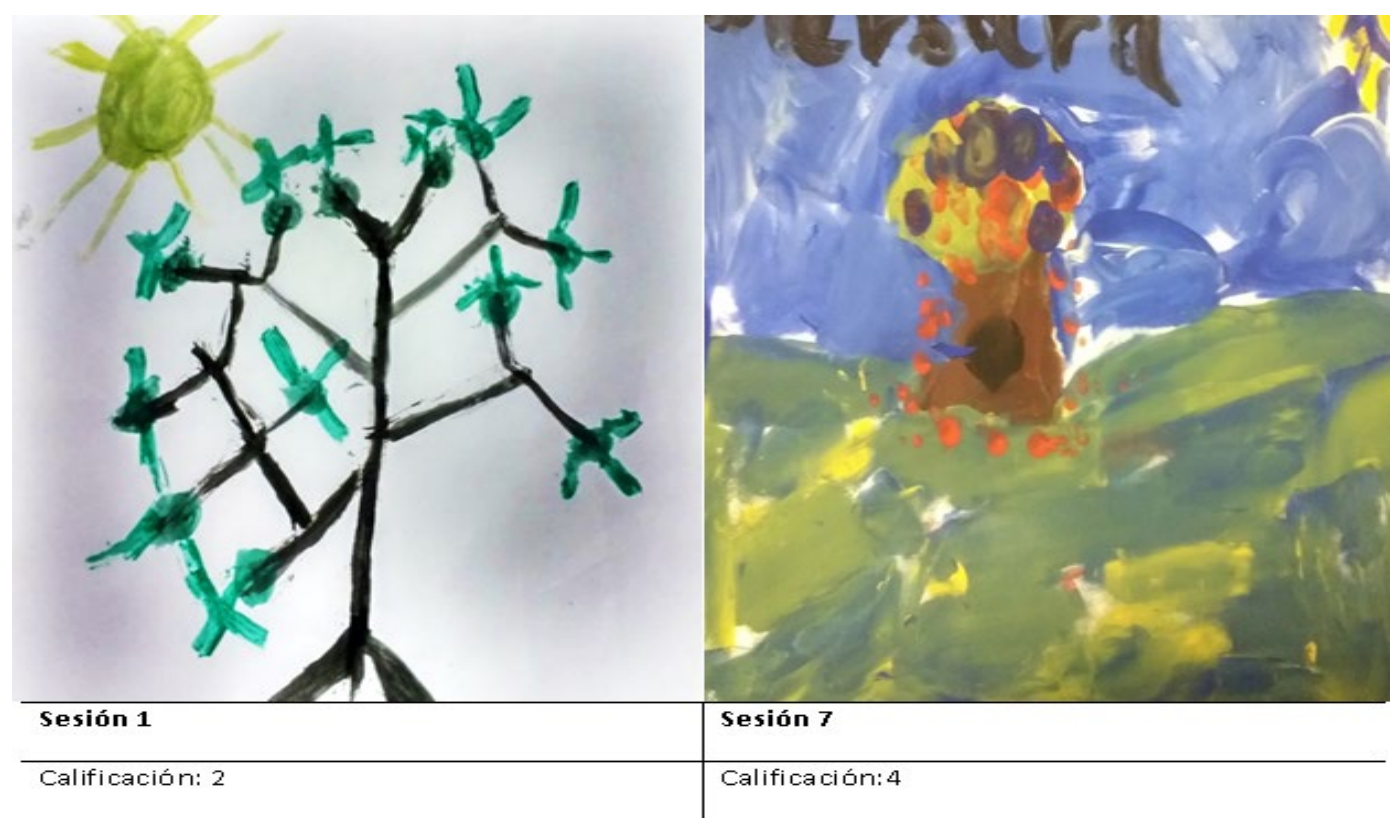

Figura 4. Comparación entre la representación de un participante de un árbol en el pre y post test

Fuente: Elaboración propia.

Otro hallazgo importante fue la asociación lineal y estadísticamente significativa entre el ítem del uso de estrategias de auto control y la medición inicial de expresar y comunicar fantasías propias $(\rho=0,849, \mathrm{p}<0,05)$. Al revisar las anotaciones de campo y las entrevistas con padres, tutores y maestros, se llegó a la conclusión de que, al compartir su imaginario propio con ellos, el participante abría una vía de comunicación y una fuente que podían usar de referente al momento de hablar sobre los sentimientos y como ejemplo para dar lecciones morales en situaciones concretas, lo cual ayuda al establecimiento de estrategias de autocontrol, no como una imposición, sino como una construcción entre el participante y su padre, tutor o maestro.

\section{Discusión y conclusiones}

Se observó un incremento en la media de las calificaciones obtenidas por los participantes en el Instrumento de Registro de Desarrollo Técnico-Expresivo del Infante en la posprueba con relación al pre test, sugiere que hubo un aumento en las capacidades gráfico-expresivas de los participantes al término de la intervención, esto se respalda con la percepción recabada en las entrevistas con padres de familia, que sugieren que sí hubo una relación entre este desarrollo y un incremento en la percepción del nivel de interacción social de los participantes, tanto en la escuela, su familia más cercana y aumentando los casos en los que los participantes iniciaban interacciones con personas oyentes no familiarizadas con la LSM. Sin embargo, no se registró un aumento significativo de los casos en los que los participantes hacían nuevos amigos de su edad fuera de la escuela.

En este sentido, se mantuvo una orientación distinta al estudio de Alegre y Villar, (2019) y Bat-Chava, Martín y Kosciw (2005), que buscaban una alineación entre la percepción de 
los padres y maestros sobre las habilidades comunicativas de los participantes; en este caso se añadió el Instrumento de Registro de Desarrollo Técnico-Expresivo del infante.

La efectividad del dibujo como medio de comunicación entre el alumno sordo y su maestro, grupo escolar y familia quedó demostrada al generar un ambiente de confianza en el grupo y mejorar su desempeño en el aula, tanto en lo académico como en lo social. Se registraron casos en los que los maestros del plantel receptor pudieron conocer aspectos de la vida de los niños que impactaban directamente en su desempeño escolar a través de sus trabajos pictóricos, de igual modo, aumentó la incidencia de casos en los que los alumnos comunicaron situaciones específicas escolares a sus padres mediante dibujos, lo cual ayudaba especialmente cuando los padres no hablaban lenguaje de señas. Sin embargo, aunque existió concordancia en los datos recabados por los diferentes instrumentos indicando que dicha competencia mostró un incremento, debido al tamaño de la muestra, rango de edad de los participantes y a la falta de un grupo de control, no es posible afirmar que el tratamiento experimental sea directamente responsable de todos los cambios observados.

En otros estudios donde se analizó la influencia de la pintura y su efecto en niños sordos, se abordó este arte desde una visión más general considerándola como parte de las artes plásticas y sobre todo con un enfoque basado en su aporte al desarrollo social entre los mismos niños sordos y como un catalizador para su aprendizaje de otras asignaturas (Camargo-Pérez y Dimas-Padilla, 2014; Corasi, Guerra y Paz, 2014; Segura, 2002). Una limitante de estos estudios anteriores que relacionan a las artes plásticas y su influencia en niños sordos y del presente estudio que solo toma en cuenta a la pintura, es que no se toman en cuenta las posibles diferencias entre las competencias, habilidades, disposición y facilidad con la que el niño puede mejorar sus capacidades para el dibujo. Algo similar a las diferencias que tienen las las personas para aprender a bailar. Aunque en el estudio de Segura (2002) se observó en todos los participantes sordos mayores aptitud y gusto por la pintura que los participantes oyentes.

Aunque los resultados presentados en esta investigación pueden resultar esperanzadores pues indican mejoría en las capacidades de comunicación en varias dimensiones de los niños sordos por medio del mejoramiento de sus habilidades en el dibujo, es necesario indagar hasta qué punto se puede cerrar la brecha que señala un aprendizaje hasta tres veces más lento que las personas oyentes y el hecho de terminar su educación básica con un desempeño menor al resto de sus compañeros (Asensio 1989; Conrad 1979; Marschark y Harrys, 1996).

En cuanto a la comprensión del vocabulario de la LSM de los participantes, se encontró concordancia entre los datos recabados de manera cualitativa con el Tevi-R, y la percepción de los padres de familia, tutores y maestros del plantel; datos que apoyan la idea de que este tratamiento experimental influyó de forma positiva al aumento del vocabulario de la LSM por parte de los participantes.

Como hallazgos adicionales a los objetivos de la investigación, se detectó un aumento en la frecuencia para la percepción de los padres sobre el seguimiento de las reglas del hogar por parte de los niños y una disminución en la frecuencia de sus episodios definidos como explosiones emocionales, pudiendo estos ser arranques de ira, llanto o euforia sin control de la fuerza que ejercían sobre otros. Lo anterior podría relacionarse con el objetivo del programa sobre desarrollar su competencia social y comunicativa, siendo esto no una conclusión, sino una hipótesis que se podría comprobar en futuros estudios. 
Existe evidencia en los testimonios de los padres de una falta de concientización sobre las herramientas de desarrollo que aportan las diferentes ramas del arte a sus hijos, así como la falta de interventores educativos que hayan accedido a este centro educativo, que tuviesen conocimiento al respecto de la aplicación de sus áreas en niños sordos. Se recomienda para futuras aplicaciones cambiar la sección numérica de la Entrevista Semiestructurada con el Padre o Tutor del Participante, para que la escala Likert defina con etiquetas la periodicidad de las acciones, por ejemplo: en lugar de usar un casi nunca, emplear una vez al mes o menos.

En cuanto al Test de vocabulario en imágenes Tevi-R de Echeverría, Herrera y Segure (1982), se recomienda realizar investigaciones sobre la posible necesidad de realizar un ajuste de acuerdo a las condiciones específicas de la población (nivel socio-económico, residencia en zona urbana o rural, pertenencia a un grupo que migra de forma periódica, por señalar algunos ejemplos). Otro hallazgo se presentó en las entrevistas con los padres o tutores, quienes expresaron que los participantes regresaban a sus hogares felices los días que recibían el tratamiento experimental, sin embargo, aunque estos comentarios se dieron en un $71,4 \%(\mathrm{n}=5)$ de las entrevistas de la posprueba, no había un ítem dedicado a ello, debido a las dificultades de tratar de medir la felicidad que traerían al estudio, se recomienda ahondar en la relación entre esta sensación de bienestar o felicidad en los participantes con las clases de pintura, ya que en estudios como el de Alcaide (2003) y Camargo-Pérez y Dimas-Padilla (2014), también se registró una elevación en la autoconfianza, optimismo, manejo de conductas indeseables y satisfacción en los participantes dentro y fuera del aula de clases. Se recomienda también realizar más estudios sobre la correlación inversa entre reconocer las emociones de otros y hacer nuevos amigos que se observó en este estudio, para descubrir sus causas en niños sordos y poner a prueba su existencia en otros casos similares.

Entre las limitaciones del presente estudio, se reconoce la poca homogeneidad entre las edades de los participantes, lo cual indica un grado distinto de madurez al momento de responder a las pruebas. Sería muy interesante repetir el estudio con mayores recursos para buscar grupos más homogéneos y considerar la posibilidad de contar con grupos de control. También sería deseable realizar estudios longitudinales que permitan discernir hasta donde los presentes resultados pudieran ser producto de una catarsis generada por la emoción de tener un nuevo maestro de dibujo que se mostró interesado con los niños.

\section{Agradecimientos}

Los autores de este texto desean agradecer al Consejo Nacional de Ciencia y Tecnología (CONACyT), a través del Programa Nacional de Posgrados de Calidad (PNPC) por el financiamiento de la presente investigación. Referencia 005359.

\section{Referencias}

Agurto, C. A. (2012). Las inteligencias múltiples en la educación para sordos. Polis, 17, 35-40.

Alcaide, C. (2003). Expresión plástica y visual para educadores. Madrid: Publicaciones ICCE.

Alegre, O. M. y Villar, L. M. (2019). Relación entre los problemas emocionales y el desarrollo del lenguaje en niños y adolescentes con dificultades auditivas. REICE. Revista Iberoamericana 
sobre Calidad, Eficacia y Cambio en Educación, 17(1), 5-23.

https://doi.org/10.15366/reice2019.17.1.001

Alegría, J. (2003). Deafness and reading. En T. Nunes y P. Bryant (Eds.), Handbook of children's literacy (pp. 459-489). Dordrescht: Kluwer Academic Publishers.

https://doi.org/10.1007/978-94-017-1731-1_24

Alegría, J. y Domínguez, A. B. (2009). Los alumnos sordos y el aprendizaje de la lectura. Revista Latinoamericana de Educación Inclusiva, 3(1), 95-111.

Anderson, R. C. y Pearson, P. D. (1984). A schema-theoretic view of basic processes in reading comprehension. En P. D. Pearson (Ed.), Handbook of reading research (p. 255-291). Nueva York, NY: Longman.

Archbold, S., Harris, M., O’donoghue, G., Nikolopoulos, T., White, A. y Richmond, H. L. (2008). Reading abilities after cochlear implantation: The effect of age at implantation on outcomes at 5 and 7 years after implantation. International Journal of Pediatric Otorhinolaryngology, 72(10), 1471-1478. https://doi.org/10.1016/j.ijporl.2008.06.016

Asensio, M. (1989). Los procesos de lectura en los deficientes auditivos. Tesis doctoral. Universidad Autónoma de Madrid, España.

Bat-Chava, Y., Martín, D. y Kosciw, J. G. (2005). Longitudinal improvements in communication and socialization of deaf children with cochlear implants and hearing aids: Evidence from parental reports. Journal of Child Psychology and Psychiatry, 46(12), 1287-1296. https://doi.org/10.1111/j.1469-7610.2005.01426.x

Beltrán, A. M. (2016). La expresión plástica como medio de comunicación, integración y desarrollo expresivo en alumnado con necesidades educativas especiales. Trabajo Fin de Máster. Universitat Jaume I, España.

Bortoi, A. M. y Brown, P. M. (2008). The social attention skills of preschool children with an intellectual disability and children with a hearing loss. Australian Journal of Early Childhood, 33(4), 25-33. https://doi.org/10.1177/183693910803300405

Camargo-Pérez, L. M. y Dimas-Padilla, S. M. (2014). El arteterapia como estrategia para estimular la inteligencia emocional de los niños, niñas y jóvenes sordos de la jornada de la mañana de la Institución Educativa Antonia Santos. Trabajo Fin de Máster. Corporación Universitaria Rafael Núñez, Colombia.

Colin, S., Magnan, A., Ecalle, J. y Leybaert, J. (2007). Relation between deaf childrens phonological skills in kindergarten and word recognition performance in first grade. Journal of Child Psychology and Psychiatry, 48(2), 139-146. https://doi.org/10.1111/j.1469-7610.2006.01700.x

Conrad, R. (1979). The deaf school child. Londres: Harper Row.

Convertino, C., Marschark, M., Sapere, P., Sarchet, T. y Zupan, M. (2009) Predicting academic success among deaf college students. Journal of Deaf Studies and Deaf Education, 14(3), 324343. https://doi.org/10.1093/deafed/enpoo5

Corasi, Y., Guerra, C. y Paz, M. (2014). Lineamientos metodológicos para la enseñanza de la lectoescritura en niños sordos. En M. Ramos (Ed.), Ciencias sociales T-I handbook (pp. 25-48). Chuquisaca: ECORFAN.

Cú Balán, G., Contreras, C. H. y Rosado, E. S. (2007). Factores lingüísticos asociados al rendimiento escolar en niños y niñas indígenas del primer ciclo escolar de escuelas primarias bilingües. REICE. Revista Iberoamericana sobre Calidad, Eficacia y Cambio en Educación, 5(5), $68-74$. 
Domínguez, A. B. y Alegría, J. (2010). Reading mechanisms in orally educated deaf adults. Journal of Deaf Studies and Deaf Education, 15(2), 136-148.

https://doi.org/10.1093/deafed/enpo33

Domínguez, A. B. y Leybaert, J. (2014). Acceso a la estructura fonológica de la lengua: Repercusión en los lectores sordos. Aula, 20, 65-81.

Domínguez, A. B., Rodríguez, P. y Alonso, P. (2011). Cómo facilitar aprendizaje de la lectura de niños sordos: Importancia de las habilidades fonológicas. Revista de Educación, 356, 353-375.

Echeverría, M. S., Herrera, M. O. y Segure, J. T. (1982). Test de vocabulario en imágenes: Tevi-R: manual de aplicación. Concepción: Editorial de la Universidad de Concepción.

Fernández, V. H. (2009). En busca de un modelo educativo y de lectura coherente con las necesidades especiales de los estudiantes sordos. REXE. Revista de estudios y experiencias en educación, 8(16), 11-24.

Fernández, V. H. (2014). Alfabetización y bilingüismo en aprendices visuales: Aportes desde las epistemologías de sordos. Educación y Educadores, 17(1), 135-148.

https://doi.org/10.5294/edu.2014.17.1.7

Gálan, S. L., Romero, P. A. L. y Buelvas, I. (2018). Manejo de la lengua de señas colombiana (LSC), en el rendimiento escolar de los niños y niñas sordos de preescolar y primero de primaria de la Institución Educativa Antonia Santos, sede Juan Salvador Gaviota-Cartagena de Indias Tesis doctoral. Universidad de Cartagena, Colombia.

Gardner, H. (1993). Multiple intelligences: The theory in practice. Nueva York, NY: Basic Books.

Herrera, V. (2005). Habilidad lingüística y fracaso lector en los estudiantes sordos. Estudios Pedagógicos, 31(2), 121-135. https://doi.org/10.4067/S0718-07052005000200008

Jiménez-Torres, M. G. y López, M. (2003). Deficiencia auditiva, evaluación, intervención y recursos psicopedagógicos. Madrid: Cepe.

Kyle, F. y Harris, M. (2010). Predictors of reading development in deaf children: A 3-year longitudinal study. Journal of Experimental Child Psychology, 107(3), 229-243.

https://doi.org/10.1016/j.jecp.2010.04.011

Leybaert, J. (1993). Reading in the deaf: The roles of phonological codes. En M. Marschark y D. Clark (Eds.), Psychological perspectives in deafness (pp. 203-227). Nueva York, NY: Laurence Erlbaum Associates.

Leybaert, J., Colin, S. y LaSasso, C. J. (2010). Cued speech for deaf students' mastery of the alphabetic principle. En C. J. LaSasso, K. Crain y J. Leybaert (Eds.), Cued speech and cued language for deaf and hard of hearing children (pp. 245-283). San Diego, CA: Plural Publishing Inc.

Lissi, M. R., Grau, V., Raglianti, M., Salinas, M. y Torres, M. (2011). Adquisición de la lectoescritura en niños sordos: Una visión desde los profesores en Chile. Psykhe, $10(1), 35-$ 48 .

Lichtenstein, E. H. (1998). The relationships between reading processes and English skills of deaf college students. Journal of deaf Studies and deaf Education, 3(2), 195-206. https://doi.org/10.1093/oxfordjournals.deafed.a014348

López-Bosch, M. A. (2000). Simbolización, expresión y creatividad: Tres propuestas sobre la necesidad de desarrollar la expresión plástica infantil. Arte, Individuo y Sociedad, 12(41), 4157 .

Lowenfeld, V. (1961). Desarrollo de la capacidad creadora. Buenos Aires: Kapelusz. 
Luque, D. J. y Romero, J. F. (2002). Trastornos del desarrollo y adaptación curricular. Málaga: Aljibe.

Marschark, M. y Harrys, M. (1996). Success and failure in learning to read: The special case of deaf children. En C. Cornoldi y J. Oakhill (Eds.), Reading comprehension difficulties: Process and Intervention (pp. 279-300). Mahwah, NJ: Lawrence Erlbaum Associates.

Marschark, M., Rhoten, C. y Fabich, M. (2007). Effects of cochlear implants on children's reading and academic achievement. Journal of Deaf Studies and Deaf Education, 12(3), 269-282. https://doi.org/10.1093/deafed/enmo13

Martín, C. (1995) Desarrollo cognitivo y problemas escolares en sordos/as. Tabanque: Revista Pedagógica, 10, 213-222.

Mayberry, R. I., Del Giudice, A. y Lieberman, A. M. (2010). Reading achievement in relation to phonological coding and awareness in deaf readers: A meta-analysis. Journal of Deaf Studies and Deaf Education. Advance Access Published, 16(2), 164-188. https://doi.org/10.1093/deafed/enq049

Melgar, J. y Moctezuma, M. (2010). La posibilidad del bilingüismo y biculturalismo en la comunidad sorda. Recuperado de https://cultura-sorda.org/wpcontent/uploads/2015/03/Melgar_Moctezuma_BiculturalismoBilinguismo_sordo_2010.pdf

Muñoz, J. G. M. y López-Aymes, G. (octubre, 2017). Preocupaciones y necesidades de padres y madres de sujetos sordos talentosos en artes plásticas. Comunicación presentada en el $X V$ Congreso Nacional de Investigación Educativa (COMIE). San Luis Potosí, México.

Musselman, C. (2000). How do children who can't hear learn to read an alphabetic script? A review of the literature on reading and deafness. Journal of Deaf Studies and Deaf Education, 5(1), 931. https://doi.org/10.1093/deafed/5.1.9

Nicholas, J. G. y Geers, A. E. (2008). Expected test scores for preschoolers with a cochlear implant who use spoken language. American Journal of Speech Language Pathology, 17(2), 12 1-138. https://doi.org/10.1044/1058-0360(2008/013)

OMS. (2001). Clasificación internacional del funcionamiento, de la discapacidad y de la salud. Ginebra: Ediciones OMS.

OMS. (2011). Informe mundial sobre la discapacidad. Malta: Ediciones OMS.

Paz, M. V. y Salamanca, M. (2009). Elementos de la cultura sorda: Una base para el currículum intercultural. REXE. Revista de Estudios y Experiencias en Educación, 8(15), 31-49.

Parra, P. D. y Luque-Rojas, M. (2013). Necesidades específicas de apoyo educativo del alumnado con discapacidades sensorial y motora. Summa Psicológica UST, 1O(2), 57-72. https://doi.org/10.18774/448x.2013.10.141

Pérez López, S. (2012) Educación artística y patrimonial como vía de acercamiento para el trabajo con el colectivo sordo. Arte, Educación y Cultura. Aportaciones desde la Periferia, 1, 14-27.

Pérez López, S. (2014). Educación artística y patrimonial para la percepción, comprensión y reflexión del colectivo sordo en el ámbito museal. Estudio de casos evaluativo. Tesis doctoral. Universidad de Valladolid, España.

Perfetti, C. A. y Sandak, R. (2000). Reading optimally builds on spoken language: Implications for deaf readers. Journal of Deaf Studies and Deaf Education, 5(1), 32-50. https://doi.org/10.1093/deafed/5.1.32

Piaget, J. (1937). La construction du reel chez l'enfant. Neuchátel: Delachaux.

Read, H. (1969). Arte y alienación. Buenos Aires: Editorial Proyección. 
Segura, B. W. (2002). La danza y la pintura con los niños sordos en espacio-temporalidad. Trabajo Fin de Grado. Universidad de la Sabana, Cundinamarca, Colombia.

Soriano, J., Pérez, I. y Domínguez, A. B. (2006). Evaluación del uso de estrategias sintácticas en lectura por alumnos sordos con y sin implante coclear. Revista de Logopedia, Foniatría y Audiología, 26(2), 72-83. https://doi.org/10.1016/So2 14-4603(06)70105-X

Spencer, P. E. y Marschark, M. (2010). Evidence-based practice in educating deaf and hard-ofhearing students. Nueva York, NY: Oxford University Press.

Swanwick, R. (2015). Re-envisioning learning and teaching in deaf education: Toward new transactions between research and practice. En H. Knoors y M. Marschark, M. (Eds.), Educating deaflearners: Creating a global evidence base (pp. 595-613). Nueva York, NY: Oxford University Press. https://doi.org/10.1093/acprof:oso/9780190215194.003.0026

\section{Breve CV de los autores}

\section{Julio Jaime Flores-Rivas}

Licenciado en Artes Plásticas Opción: Pintura y Maestro en Innovación Educativa por la Universidad Autónoma de Chihuahua. Encargado del Taller de dibujo y pintura del Instituto de Pensiones Civiles del Estado de Chihuahua. Cuenta con 13 años de experiencia como docente. Además de capacitarse para poder acercar la práctica artística a niños con Asperger, Autismo y Síndrome de Down, se preparó en LSM para sus estudiantes con cualquier grado de sordera. ORCID ID: https://orcid.org/0000-00024790-5742. Email: goro_fuyita@hotmail.com

\section{Fidel González-Quiñones}

Catedrático investigador de tiempo completo en la Facultad de Filosofía y Letras de la Universidad Autónoma de Chihuahua (UACH). Licenciado en Ciencias de la Información, MBA en Recursos Humanos y MBA en Marketing. Es Doctor en Periodismo Social por la Universidad de Sevilla (España). Es analista de datos, cuenta con más de 15 años de experiencia como conferencista e investigador y actualmente dirige el Centro Estratégico de Investigación de la $\mathrm{UACH}$ en el que desarrolla estudios interdisciplinarios con particulares, empresas y entidades de gobierno estatal y federal. Miembro del Cuerpo Académico Consolidado UACH-CA-088 de Estudios de la Información. ORCID ID: https://orcid.org/0000-0002-8404-0098. Email: fgonzalez@uach.mx 